\title{
Professor, ensino e avaliação: uma perspectiva à luz do racionalismo bachelardiano
}

\section{Teacher, teaching and evaluation: a perspective in the light of bachelardian rationalism}

\author{
Ana Cléa Gomes de Sousa ${ }^{1}$ \\ Marcos Antonio Martins Lima ${ }^{2}$
}

\begin{abstract}
Resumo
Parte-se da compreensão de que o racionalismo aplicado de Gaston Bachelard (1884-1962) contém aspectos que podem contribuir com a prática pedagógica dos professores e retroalimentar o ensino e a avaliação, uma vez que a intencionalidade do racionalismo bachelardiano encontra-se assente na possibilidade de retificar o conhecimento, em um movimento dialético. Portanto, este artigo, de viés bibliográfico, tem por objetivo apresentar, de um modo geral, elementos existentes na epistemologia de Bachelard que dialogam com o trabalho pedagógico do professor e, por conseguinte, com a avaliação institucional. Recorreuse a quatro obras do autor escritas entre 1934 e 1949. Conclui-se apontando contributos bachelardianos ao ensino que serão basilares para o desenvolvimento da pesquisa de doutoramento iniciada em 2018.
\end{abstract}

Palavras-chave: Racionalismo bachelardiano; Competências profissionais docentes; Avaliação de professores.

\begin{abstract}
It begins with understanding that the applied rationalism of Gaston Bachelard (1884-1962) contains aspects that can contribute to the pedagogical practice of teachers and to retrofeed the teaching and evaluation, since the intentionality of Bachelardian rationalism is based on the possibility of rectifying the knowledge in a dialectical movement. Therefore, this article, with a bibliographic bias, aims to present, in general, elements existing in the epistemology of Bachelard that dialogue with the pedagogical work of the teacher and, therefore, with the institutional evaluation. Four works by the author written between 1934 and 1949 were researched. It concludes by pointing out Bachelardian contributions to teaching that will be basic for the development of doctoral research initiated in 2018.
\end{abstract}

Keywords: Bachelardian rationalism; Teaching professional skills; Teacher evaluation.

\footnotetext{
1 Doutoranda em Educação na Universidade Federal do Ceará. Pedagoga no Instituto Federal de Educação, Ciência e Tecnologia do Ceará, Sobral, Ceará, e-mail: anasousa@ifce.edu.br. Orcid: https://orcid.org/0000-00021535-1351.

2 Doutor em Educação pela Universidade Federal do Ceará. Pós Doutor em Gestão pela UFRN. Professor Associado na Universidade Federal do Ceará (UFC), Fortaleza, Ceará, e-mail: marcoslimaiag@gmail.com. Orcid: https://orcid.org/0000-0001-5541-6220.
} 


\section{OO DEVIR EDUCAÇÃO}

ISSN: 2526-849X

\section{Introdução}

A epistemologia, compreendida como ramo da filosofia que estuda a origem do conhecimento e as questões relativas à sua validade (LIMA, 2008), permite vigilância crítica e reflexão. Ambas exigem disciplina do pesquisador ao longo de todo o seu percurso para ampliar a compreensão acerca das especificidades do conhecimento e das relações que ocorrem entre sujeito e objeto.

A concepção da epistemologia utilizada nesse estudo não é de uma doutrina analíticonormativa, mas, sim, de uma tomada de consciência metodológica que, por estar animada por uma preocupação eficaz da radicalidade, nem por isso deixe de se reconhecer inacabada, sempre suspensa a uma exigência indefinida de autocompreensão, que evidentemente só pode permanecer sempre insatisfeita (BRUYNE et al 1977).

Este artigo tem por objetivo apresentar, de um modo geral, elementos existentes na epistemologia de Gaston Bachelard (1884-1962) que dialogam com o trabalho pedagógico do professor e, por conseguinte, com a avaliação institucional. Trata-se, portanto, do resultado da conduta metodológica adotada para iniciar a pesquisa no âmbito do Doutorado em Educação em curso na Universidade Federal do Ceará, cujos aspectos epistemológicos constituíram da aproximação em torno do fenômeno investigado, cujo cerne reside na avaliação de competências docentes em uma instituição pública vinculada à Rede Federal de Educação, Profissional Científica e Tecnológica (EPCT). Vale ressaltar que, embora a variável competência docente não expresse a amplitude da avaliação institucional na unidade de EPCT analisada, todavia a existência de dois processos de avaliação de desempenho com funções distintas (formativa e somativa) voltados para os professores justificam o vínculo estabelecido durante o estudo.

Parte-se da compreensão de que o racionalismo aplicado de Gaston Bachelard contém aspectos que podem contribuir com a prática pedagógica dos professores e retroalimentar o ensino e a avaliação, uma vez que a intencionalidade do racionalismo bachelardiano encontrase assente na possibilidade de se retificar o conhecimento em um movimento dialético e este é, essencialmente, um diálogo. Se, para esse filósofo, o erro é fonte de aprendizagem e retroalimentação do espírito científico, então há elementos pedagógicos em seu pensamento que podem nutrir a ação docente do professor frente aos seus alunos.

Revista Devir Educação, Lavras, vol.4, n.2, p.272-290 jul./dez., 2020. 


\section{OO DEVIR EDUCAÇÃO}

ISSN: 2526-849X

A necessidade de as novas descobertas realimentarem as teorias existentes tornou as salas de aulas ambientes ainda mais complexos que, a um só tempo, são formais e informais, lineares e não-lineares. Nesse sentido, o papel do professor, na atualidade, é dar sentido ao conhecimento por meio da necessária relação teórico-prática.

Para Bachelard (1996), um dos obstáculos para a formação do espírito científico é a experiência primeira que, colocada antes e acima da crítica, torna a base do conhecimento frágil. Para o autor, experiências muito marcantes e cheias de imagens podem ser falsos centros de interesse para os alunos. Portanto, torna-se indispensável que o docente passe da mesa de experiências para o quadro, a fim de extrair o abstrato do concreto, pois, quando voltar à experiência, estará mais preparado para distinguir os aspectos orgânicos do fenômeno.

Ao refletir sobre reformas realizadas no Ensino Médio da França entre 1928 e 1938 por meio da quais se diminuíram dificuldades dos problemas de Física, ao implantar, em certos casos, um ensino de Física sem problemas, feito só de perguntas orais, que desconhecem o real sentido do espírito científico - Bachelard (1996) assevera que mais vale a ignorância total do que um conhecimento esvaziado de seu princípio fundamental. Com tal proposição, o autor defende o equacionamento racional da experiência por meio da qual se dá a formulação de um problema no qual, para ser racionalizada, a experiência precisa ser inserida em um jogo de razões múltiplas.

$\mathrm{Na}$ perspectiva bachelardiana, todas as filosofias do conhecimento científico organizam-se a partir do racionalismo aplicado, motivo pelo qual ele o define como de posição central frente ao idealismo, convencionalismo, formalismo, materialismo técnico, positivismo, empirismo e realismo.

Os pressupostos da pedagogia científica são, de certa forma, inseparáveis dos pressupostos epistemológicos que fundamentam o novo espírito científico discutido por Bachelard. Trata-se, pois, da necessária problematização que deve fundamentar a ação dos professores, não somente na pesquisa, mas, sobretudo, no ensino dos estudantes, seja na Educação Superior ou na Educação Profissional, Científica e Tecnológica (EPCT), nos dias atuais.

Bachelard, em seu postulado, apresenta a necessidade de as novas descobertas realimentarem as teorias existentes. A atividade científica requer uma interligação entre o racional e o real. De acordo com Lima (2008), um novo espírito científico foi atingido no 


\section{OO DEVIR EDUCAÇÃO}

ISSN: 2526-849X

início do século XX, com a Teoria da Relatividade de Einstein, a Mecânica Quântica, a Teoria da Ondulatória, a Geometria Não-Euclidiana e com a aproximação entre a Matemática e a experiência. Desse modo, desponta uma nova epistemologia, em que o empirismo e o racionalismo, até então vistos como dicotômicos, devem ser solidários. Trata-se, pois, do racionalismo aplicado.

Ocorre que não há racionalidade no vazio, tampouco empirismo desconexo. De acordo com Bachelard (1977), tal certeza expressa-se via diálogo entre técnica e razão. Portanto, é necessário que o racionalismo esteja aberto para receber determinações novas das experiências, em que "[...] a epistemologia deve, então, ser tão móvel quanto a ciência" (BACHELARD, 1977, p. 17).

Lima (2008) afirma que, apesar das críticas recebidas por historiadores e filósofos, o pensamento de Bachelard é original, pois propõe novas categorias epistemológicas (ruptura, corte, obstáculo, recorrência e vigilância), sobretudo por revolucionar a história das ciências com uma abordagem pedagógica guiada pela polêmica e pela finalidade de denunciar o erro da razão. A ruptura epistemológica determina o nascimento de uma nova ciência. Em Bacherlard, o progresso do conhecimento ocorre por meio de rupturas e não por simples acúmulo de conhecimento. Os cortes epistemológicos são as descontinuidades na produção do saber científico. Em outras palavras, trata-se do início de uma ciência que, embora considere sua historicidade e noções anteriores, nasce a partir da própria renovação. Já os obstáculos epistemológicos são os preconceitos que impedem o surgimento do real, de novas ideias e do progresso da ciência. A recorrência corresponde ao entendimento do conhecimento como incerto, provisório e inacabado; a vigilância traduz-se em crítica, situada tanto na lógica da descoberta quanto na lógica da prova. Assim, enquanto a descoberta ocupa-se do exame do processo de produção dos objetos, a prova volta-se para a análise dos procedimentos da validação no âmbito das práticas científicas (LIMA, 2008; LIMA; MARINELLI, 2011; COSTA, 2015).

Bachelard defende, portanto, que é preciso colocar razão e objeto numa dialética de cooperação. Com efeito:

$\mathrm{O}$ racionalismo aplicado de Bachelard aproxima-se do racionalismo de Brunschivicg como uma espécie nova que detém características de um importante ancestral. Ambos rejeitam o empirismo e o idealismo puro e consideram que o mundo, construído pela ciência, não é o produto de 


\section{OO DEVIR EDUCAÇÃO}

ISSN: 2526-849X

representação ou de convenção, mas é resultante de verificação (LIMA, 2008, p. 131).

Fonseca (2008) corrobora essa ideia ao destacar que a discussão teóricoepistemológica de Bachelard torna-se importante para o pensamento pedagógico, uma vez que os pressupostos da pedagogia científica são inseparáveis dos pressupostos epistemológicos que fundamentam o novo espírito científico. "[...] Bachelard defende uma filosofia racionalista e aplicada, porém, diferente do cartesianismo, e também antipositivista, crítica e polêmica [...]." (LIMA, 2008, p. 121).

Portanto, Bachelard (1977, p. 30) traz importante contribuição não só para o pensamento pedagógico, mas, sobretudo, para as práticas que orientam a pesquisa científica. Conforme seu pensamento:

De fato numa educação de racionalismo aplicado, numa educação de racionalismo em ação de cultura, o mestre apresenta-se como negador de aparências, como freio de convicções rápidas. Ele deve tomar mediato o que a percepção proporciona imediatamente. De modo geral ele deve entrosar o aluno na luta das idéias e dos fatos, fazendo-o observar bem a inadequação primitiva da ideia com o fato.

As proposições do pensador para o racionalismo docente e para o racionalismo ensinado são instigantes, pois revelam, além da consciência do erro, que toda filosofia da cultura $^{3}$ deve acolher a noção de níveis pedagógicos. Assim, para o autor, toda cultura é solidária com o plano e com o ciclo de estudos. A pessoa afeita à cultura científica é um eterno estudante. Assim, “[...] a escola é o modelo mais elevado da vida social. Continuar sendo estudante deve ser o voto secreto de todo professor". (BACHELARD, 1977, p. 31).

Podem-se destacar aspectos pedagógicos relevantes para os professores na epistemologia de Gaston Bachelard, quais sejam: (i) a inversão de papeis entre mestre e alunos, num movimento dialético constante; (ii) o erro como possibilidade de conhecimento; (iii) a aprendizagem discente como condição para a compreensão do objeto e (iv) a negação da cultura científica, uma vez que só há ciência por uma escola permanente.

O primeiro elemento relaciona-se ao fato de o espírito científico formar-se enquanto se reforma. Trata-se não só de um movimento dialético, mas, também, da necessidade de o

\footnotetext{
${ }^{3}$ Há cultura na proporção em que se elimina a contingência do saber; mas essa eliminação, jamais completa, também nunca é definitiva. Ela deve ser refeita incessantemente (BACHELARD, 1977).
} 


\section{OO DEVIR EDUCAÇÃO}

ISSN: 2526-849X

professor se colocar na condição de aprendente enquanto ensina e/ou pesquisa. O segundo diz respeito ao importante aspecto do racionalismo aplicado, que é o erro, entendido não como fracasso, mas como oportunidade de aprimoramento. $\mathrm{O}$ terceiro encontra amparo no racionalismo ensinado, por meio do qual compreender é uma emergência do saber. "[...] $\mathrm{O}$ professor será aquele que faz compreender - e na cultura mais avançada em que o aluno já compreendeu - será aquele quem fará compreender melhor" (BACHELARD, 1977, p. 27). No quarto elemento, reside o Cogitamus $^{4}$, princípio criado em 1938, hoje conhecido como educação permanente (aprendemos sempre). Uma cultura bloqueada num tempo escolar é a negação da cultura científica. Então, nessa perspectiva, só há ciência por uma escola permanente, onde os interesses sociais se invertem: a sociedade será feita para a escola, e não mais a escola para a sociedade, conforme Japiassu (1975).

Dessa maneira, tomar-se-á o racionalismo aplicado como fio condutor frente às reflexões a serem realizadas ao longo do estudo, considerando que a consciência avaliativa permite transformar o saber pré-científico em novo saber científico (LIMA, 2008).

Assim, as discussões adiante buscaram apoio em aspectos da epistemologia bachelardiana, considerando a relação estabelecida com o tema avaliação de competências docentes, objeto de estudo na pesquisa de doutoramento em andamento, notadamente no que tange à prática pedagógica docente em uma instituição vinculadas à rede federal de EPCT. Nesta rede, o ensino, a pesquisa e a extensão, embora conformem o princípio da indissociabilidade, desencadeiam, no cotidiano dos professores, incertezas e dúvidas a serem despertadas, esses elementos são fundamentais, pois exigem do docente uma capacidade de olhar para sua própria prática, buscando melhorá-la.

\section{Procedimento metodológico}

Esta pesquisa, de viés bibliográfico, considera que o pesquisador encontrará, na reflexão epistemológica, não apenas os fundamentos para o rigor e precisão dos seus procedimentos, mas, também, elementos para evitar os obstáculos e fazer progredir o conhecimento (BRUYNE et al, 1977).

Para realizar as discussões contidas nos dois itens adiante expostos, recorreu-se às

\footnotetext{
${ }^{4}$ Bachelard substitui o Cogito cartesiano por um Cogitamus. Um homem só, diz ele, é uma péssima companhia. Aprendemos sempre (JAPIASSU, 1975).
}

Revista Devir Educação, Lavras, vol.4, n.2, p.272-290 jul./dez., 2020. 


\section{QO DEVIR EDUCAÇÃO}

ISSN: 2526-849X

seguintes obras de Gaston Bachelard: O novo espírito científico, escrito em 1934; A formação do espírito científico, escrito em 1938; A filosofia do não: filosofia do novo espírito científico, escrito em 1940 e O racionalismo aplicado, escrito em 1949.

O primeiro item apresenta alguns contributos pinçados da pedagogia científica de Bachelard para o ensino dos professores nos dias atuais. O segundo aborda avaliação e competência docente, considerando as proposições do autor sobre qualidade e quantidade destacando a noção de competência bachelardiana a partir da relação em torno do fazer e do saber.

\section{Contributos bachelardianos ao ensino}

A noção de obstáculo epistemológico ${ }^{5}$ é indispensável para compreender os valores do racionalismo aplicado, uma vez que esses obstáculos são inerentes à ciência. Todavia, a aplicação do racionalismo deverá sempre considerar um racionalismo do contra, que subjaz a uma ação contínua sobre os erros contidos nas experiências primeiras. Portanto, a razão trabalhará contra si mesma, de acordo com Gaston Bachelard.

Ocorre que o pensamento científico está em estado de pedagogia permanente, uma vez que:

[...] admite na descrição fenomenológica de um conhecimento que se tenha eliminado todo o psicologismo de modo a atingir um limite objetivo, restará sempre o fato de que não se deverá tomar consciência da passagem ao limite sem renovar de maneira mais ou menos explícita essa eliminação. Desse modo, acrescentamos, à regra do desmembramento das ideias justas, uma regra do exorcismo explicito das ideias falsas. (BACHELARD, 1977, p. 23).

Portanto, há sempre um psicologismo persistente nas ideias, uma vez que a noção de função epistemológica de uma essência não pode ser desvencilhada de todo o psicologismo, pois este é indispensável no racionalismo docente. Assim, o autor afirma que, ao estudar a epistemologia no nível do racionalismo docente, somos levados a prestar grande atenção no

5 São ideias que bloqueiam a passagem do pensamento pré-científico para o espírito científico. Bachelard, no livro "A formação do espírito científico", identifica os seguintes obstáculos epistemológicos: a experiência primeira; o conhecimento geral ou generalização; o verbalismo; conhecimento unitário e pragmático; o obstáculo substancialista; o obstáculo animista; e o conhecimento quantitativo (BACHELARD, 1996). 


\section{OO DEVIR EDUCAÇÃO}

ISSN: 2526-849X

pluralismo das demonstrações para um único e mesmo problema. Desse modo, as essências deixam a sua supremacia celestial para apresentar-se como resultados de experiências racionais.

Bachelard é alvo de críticas no que concerne ao seu conceito de obstáculo epistemológico, embora tenha reservado a este tema atenção especial ao longo de sua obra, de acordo com Lima (2008). Não obstante, em seus estudos sobre a epistemologia bachelardiana, este pesquisador destaca o fato de que, junto à variável psicológica, há, também, a presença da variável ideológica, evidenciada quando Bachelard discute a possibilidade de uma educação equivocada sobre a ciência contemporânea.

Se, numa perspectiva bachelardiana, o mais simples é acompanhar as ideias no movimento de transformação sob o qual se constitui o ensino, então, situar o professor, o aluno e o próprio ensino no campo interpsicológico possibilita a formação do interracionalismo, que vem a ser o racionalismo comprovado. Portanto, é nessa transformação das ideias que, para Bachelard (1977), reside o fato de o racionalismo ensinado - entendido como um momento do trajeto cultural, que vai do real percebido à experiência realizada verificar-se na tomada de estrutura como valor. Isto é, sob essa óptica, compreender é uma emergência do saber. Assim, o professor será aquele que faz compreender, e o aluno será aquele que compreenderá melhor a cada momento do seu trajeto. E o ensino será aquele fortalecido na dialética professor-aluno.

Como o eco dessa compreensão sobre o ensino chega ao professor e ao aluno? Ou, que entendimentos o inter-racionalismo bachelardiano ${ }^{6}$ captado na dialética professor-aluno pode provocar nos educadores de hoje?

Ocorre que o formalismo do raciocínio pode enganar porque há desproporção entre a facilidade do empirismo da constatação, de um lado, e a dificuldade pedagógica da construção racional, de outro. Todos esses valores epistemológicos diferenciam-se num ensino efetivo, pois, de acordo com Bachelard (1977, p. 29):

O mesmo aconteceria em um ensino filosófico em que uma tese sobre o conhecimento se acompanhasse de aumento positivo de conhecimento, e não se contentasse com algumas referências ao conhecimento vulgar ou com um conhecimento científico adormecido. [...] Desse modo, o inter-racionalismo

\footnotetext{
${ }^{6} \mathrm{Na}$ perspectiva de Bachelard todo racionalismo é inter-racionalismo, uma vez que em sua teoria a ciência não é um continuum, mas, sim, um devir em constante recomeço por meio de rupturas que ocorrem pela retificação dos erros (BACHELARD,1977).
}

Revista Devir Educação, Lavras, vol.4, n.2, p.272-290 jul./dez., 2020. 


\section{OO DEVIR EDUCAÇÃO}

ISSN: 2526-849X

em formação que podemos captar na dialética professor-aluno é filosoficamente mais rico de ensinamento que o racionalismo em forma.

Uma das funções do ensino científico é suscitar dialéticas. Desse modo, para o autor, integração e diferenciação são igualmente valores do inter-racionalismo. Nesse sentido, o professor deve preocupar-se menos com o fundamento do que com o trabalho efetivo do racionalismo, pois ele aparece como uma filosofia muito mais engajada do que o admitem seus críticos.

Todavia, essa noção de engajamento não deverá impedir que o professor perceba o sentido das ações inter-racionalistas, uma vez que estas devem assentar-se em desligamentos prévios a todo compromisso. Caso contrário, teríamos um obstáculo ao racionalismo docente (a ação do professor) e ao racionalismo ensinado (o aprendizado do aluno), pois, de fato, numa educação de racionalismo aplicado, o professor apresenta-se não só como um negador das aparências, mas, também, como um freio a convicções rápidas. Tem por missão tomar por mediato o que a percepção suscita como imediato e, assim, conseguirá conduzir o aluno a ir além das experiências.

Bachelard lembra que toda filosofia de cultura deve acolher a noção de níveis pedagógicos, uma vez que toda cultura é solidária com plano e ciclo de estudos pedagógicos. Portanto, para o autor, a pessoa afeita à cultura científica é um eterno estudante. Continuar sendo estudante deve ser o voto secreto de todo professor (BACHELARD, 1977). Nesse sentido, a dialética professor e aluno inverte-se sempre.

Portanto, a formação do espírito científico não é somente a reforma do conhecimento vulgar é, sobretudo, conversão de interesse, na qual reside o engajamento científico, que se assenta na necessidade de abandonar os primeiros valores. Por isso, entende-se que tanto no trabalho científico como na ação dos professores na atualidade os valores transformam-se, pois ciência e educação renovam-se constantemente.

É na instância pedagógica que se encontra um aspecto relevante na pedagogia científica de Bachelard, pois é nesse ponto que um ensino fortalecido na dialética professoraluno poderá ecoar, provocando novos entendimentos no tocante ao devir do pensamento científico nos mestres/educadores e nos seus alunos, já que estes dois sujeitos estão inscritos no cogitamus - decisivamente discursivo - proposto por Bachelard. Desse modo, pode-se inferir que há, nos ecos trazidos pela pedagogia científica de Bachelard, um contributo ao ensino nos dias atuais, considerando que nenhum saber é, por si só, formador, pois saber 
alguma coisa não é o suficiente; é preciso saber ensinar, conforme proposições de Tardif (2011).

Bachelard (1977) corrobora o pensamento desse autor ao afirmar que, quando se realiza um cálculo e decide-se voltar a este para revê-lo, a fim de verificar se houve engano, esse retorno à ação representa dois atos distintos: o julgamento e o cálculo. Mas, sobretudo, revelam um desdobramento de si e um esforço pedagógico. Desse modo, na perspectiva bachelardiana, o esforço pedagógico constante do racionalismo docente e ensinado desvelará, não somente a inversão de papeis na dialética professor-aluno, mas, sobretudo, o rigor contra todos os obstáculos/enganos possíveis. Este também pode ser tomado como uma contribuição ao ensino dos professores na atualidade, notadamente daqueles que se ocupam do ensino superior e/ou da EPCT.

Na obra O novo espírito científico, escrita em 1934, Bachelard analisa um procedimento pedagógico nas proposições de Werner Karl Heisenberg ${ }^{7}$ (1901-1976), qual seja, o da necessidade de dupla experiência. Em que consiste a dupla experiência heisenberguiana?

Nos princípios físicos da Teoria dos Quanta, após uma breve introdução, Heisenberg desenvolve dois capítulos antagônicos. O primeiro consiste em criticar as noções físicas da teoria corpuscular, apoiando-se nas noções físicas da teoria ondulatória, conferindo, por conseguinte, uma validade prévia às noções desta última. O segundo transforma as objeções, uma vez que seu foco é criticar as noções físicas da teoria ondulatória, apoiando-se nas noções físicas da teoria corpuscular tomadas, nesse segundo, momento como válidas.

Na verdade, essa crítica dialética é uma excelente lição de filosofia fenomênica, pois, de acordo com Bachelard (1978a, p. 132):

Ela é necessária para colocar corretamente os problemas, à parte os arrebatamentos realistas. Basta percorrer os dois capítulos para notar a vantagem psicológica que deles se tira. Tomando-se o primeiro, recebe-se à primeira vista - excelente higiene intelectual - o choque dos paradoxos da mecânica ondulatória: é preciso construir a mecânica com a óptica. As noções de velocidade, de corpúsculo, de energia, de posição são noções a explicar, a construir. Não são mais explicativas. O valor de explicação passou às noções ondulatórias.

\footnotetext{
${ }^{7} \mathrm{O}$ princípio da incerteza de Heisenberg representa uma correção objetiva dos erros, representando, desse modo, uma relação que fornece, por si, um verdadeiro método (BACHELARD, 1978a).
} 


\section{OO DEVIR EDUCAÇÃO}

ISSN: 2526-849X

Portanto, junto à ação pedagógica positiva (que consiste em acentuar todas as lições fornecidas pelos fenômenos ondulatórios), há uma espécie de educação negativa (que busca arruinar o realismo ingênuo) no procedimento de Heisenberg. Nesse sentido, o complemento bachelardiano à compreensão em torno do procedimento pedagógico da dupla experiência reforça não somente o papel da ação pedagógica positiva consubstanciada por uma educação negativa que possibilite o aluno ver o que há de inacabado e gratuito na realidade, mas, também, evidencia o fato de o conhecimento renovar-se pelos erros tomados como fonte de retificação e aprimoramento.

Portanto, o contributo bachelardiano ao ensino dos professores na atualidade reside na pedagogia da razão, circunscrita no novo espírito científico, o qual, por natureza, deve ser revolucionário e, para tal, exigirá de todos os que se ocupam da educação científica/escolar uma ciência/pedagogia que seja capaz de revolucionar o conhecimento por meio de um movimento de objetivação, complexificação e constante retificação.

\section{Avaliação e competência docente em Bachelard}

A crítica de Bachelard no tocante aos instrumentos e técnicas adotados pelos pesquisadores no século XVIII permite posicionar o seu pensamento no campo da avaliação, pois, de acordo com Souza (2016), o que de fato ocorria era uma tentativa de precisar os resultados empregando instrumentos que não permitiam medir o objeto de estudo, tampouco avaliar os resultados esperados. Nas palavras da autora (SOUZA, 2016, p. 28):

O que se constata é que a ciência cumpre um protocolo, onde ocorre primeiro a leitura das experiências anteriores para manter a tradição cultural científica da época que era engessada, mas refletindo, podemos observar ainda hoje essas ocorrências, pois se valoriza muito mais nos trabalhos científicos o que já foi dito, que o que se tem de novo a dizer. Isso ocorre quando se apresenta a experiência anterior como parte da experiencial atual, mas para Bachelard isso não é possível, pois ele acredita na experiência do fenômeno e na ruptura com os conhecimentos anteriores.

A pesquisadora, ao discutir a epistemologia de Bachelard, destaca a importância de enfatizar a avaliação em cada área científica, com suas especificidades sem, contudo, considerá-las como projetos únicos aplicados de forma globalizada.

Em suma, se, para Bachelard, o conhecimento tem valor de reorganização, então a 


\section{OO DEVIR EDUCAÇÃO}

ISSN: 2526-849X

avaliação, compreendida em sua gênese como pensar, conhecer, valorar e aprimorar o objeto, renova-se pelo conhecimento científico em atos simultâneos e inter-relacionais. Conhecer para avaliar e, por conseguinte, avaliar para conhecer e aprimorar o conhecimento.

Se, para Bachelard, não existe verdade primeira, mas, sim, primeiros erros, então a essência da avaliação é (ou deveria ser) o aprimoramento constante, estando contido neste conceito um diálogo retificador entre as dimensões formativa e somativa da avaliação. Então, como melhorar um projeto avaliativo, sobretudo nas instituições de ensino superior/EPCT, sem que professores e alunos questionem e duvidem do processo avaliatório praticado em suas dimensões interna e externa? Esse é um desafio premente: a meta-avaliação e o autoconhecimento institucional.

Se a ciência descreve e interpreta a realidade, e a avaliação, além de descrevê-la, qualifica-a, então o ato de avaliar é uma investigação, conforme Luckesi (2011). Para esse autor, sem os conhecimentos emergentes do ato de avaliar - como um ato de investigação científica -, a ação pedagógica e seus resultados serão aleatórios e, possivelmente, insatisfatórios. Portanto, “[...] ao desvendar a qualidade da realidade, a avaliação oferecerá ao gestor de uma ação ou de uma instituição bases consistentes para suas decisões e o seu agir" (LUCKESI, 2011, p. 171).

Certificação (objeto pronto) e acompanhamento (objeto em construção) são dois fins vinculados à prática avaliativa docente e institucional que Luckesi (2011) discute como investigação e meios para a intervenção. As duas finalidades encontram-se subsumidas pelos conceitos somativo e formativo da avaliação traçados por Michael Scriven (1928-atual) em seu ensaio intitulado Methodology of Evaluation publicado em 1967 (VIANNA, 2000). A dimensão formativa foca no aprimoramento da pessoa/programa/instituição avaliada. Por isso, ocorre durante a ação. Já a somativa, objetiva julgar o valor e o mérito para a tomada de decisão, ocorrendo, pois, após a ação (SCRIVEN, 2018).

Em Bachelard, há uma razão inesgotável de renovação do espírito científico e, consequentemente, do conhecimento. "Toda e qualquer verdade nova nasce apesar da evidência, toda e qualquer experiência nova nasce apesar da experiência imediata" (BACHELARD, 1978a, p.93). Portanto, ao posicionar-se entre o realismo e o racionalismo, o autor convida à aprendizagem, ancorada em um movimento duplo e fundamental, pelo qual a ciência simplifica o real e complica a razão em busca de novas relações desveladas por um conhecimento retificado.

Revista Devir Educação, Lavras, vol.4, n.2, p.272-290 jul./dez., 2020. 


\section{OO DEVIR EDUCAÇÃO}

ISSN: 2526-849X

Ocorre que não se mostra o real e, sim, demonstra-se (BACHELARD, 1978b). Nesse sentido, o objeto apresenta-se como uma estrutura complexa de relações, que exigirá compreensão das suas características. Portanto, é oportuno ancorar a avaliação a partir das relações entre objeto e conhecimento, uma vez que isso, na perspectiva bachelardiana, significa dizer que, para chegar à objetivação, é necessário expor, de maneira discursiva, os métodos para identificar relações.

Desse modo, assim como no campo da avaliação, Bachelard propõe um olhar sobre a qualidade e a quantidade. Em $O$ novo espírito científico, o autor suscita um posicionamento sobre o estudo da qualidade pela quantidade, pois esta seria meio para definir o caráter indefinível das qualidades particulares de um objeto. Em suas palavras (BACHELARD, 1978a, p. 123):

Volta a substituir a descrição pela equação, a qualidade pela quantidade, e esta última substituição não aparece aqui como uma espécie de abandono filosófico. [...] Efetivamente deve-se compreender doravante que há mais e não menos numa organização quantitativa do real do que numa descrição qualitativa da experiência. A qualidade, encontrá-la-emos, com sua delicadeza, ao nível dos fenômenos compensados, nas inconsistentes propriedades dos conjuntos, como um pobre aspecto geral e vago, como um resumo sempre unilateral. Estudando as flutuações da quantidade, teremos meios para definir o caráter indefinível das qualidades particulares.

Não obstante, Lima (2008), ao discutir quantidade e qualidade em Bachelard, assevera que a avaliação quantitativa, dotada de excesso de precisão, apresenta problemas tão graves como aquela de natureza qualitativa, quando se excede nas descrições subjetivas. $\mathrm{O}$ autor advoga por métodos múltiplos que integrem a avaliação quantitativa e a qualitativa como meio para o conhecimento do objeto. É fato que "[...] é preciso refletir para medir, em vez de medir para refletir" (BACHELARD, 1996, p. 135 apud LIMA 2008).

Em sua tese, o pesquisador discute a superação do binômio quantidade-qualidade sob a ótica bachelardiana, a qual propõe não só descrever o objeto, mas, sobretudo, adotar a reflexão como condição para melhor medir/avaliar e identificar as relações existentes em torno do objeto estudado.

De forma complementar, as discussões de Souza (2016, p. 24-38) convidam a pensar na avaliação a partir do delineamento de seu objeto, uma vez que sem este, sem um objetivo ou uma técnica, ela perderá o seu sentido. Seria o mesmo que tentar pensar sobre o 


\section{OO DEVIR EDUCAÇÃO}

ISSN: 2526-849X

conhecimento sem especificá-lo. A autora, ancorada na epistemologia de Bachelard, lembra que o erro deve ser tomado como um propulsor do conhecimento científico, sendo necessário, àquele que busca o conhecimento, desvencilhar-se de suas primeiras impressões e supostas certezas.

Discutir avaliação e competência docente à luz de Bachelard constitui-se em um desafio, pois, embora outros estudos no campo das ciências da educação tenham se ocupado das ideias desse filósofo/professor (LIMA, 2008; COSTA, 2015; SOUZA, 2016;), parece oportuno buscar, nesse epistemólogo, aspectos basilares para discussões em torno da complexidade do trabalho docente e, por conseguinte, da avaliação de suas competências na atualidade, tomando, sobretudo, como ponto de referência, a educação profissional científica e tecnológica.

Embora Gaston Bachelard não tenha criado uma corrente teórico-pedagógica ou se tenha criado no século XXI uma pedagogia escolar bachelardiana, conforme estudos de Costa (2015), a existência, em sua obra, de diversos relatos sobre a atuação do professor em sala de aula representa - além do posicionamento do filósofo sobre a racionalidade como orientadora do conhecimento - um incentivo à pesquisa e à reflexão crítica sobre o ensino e sobre as competências requeridas dos professores.

Se, em Bachelard (1978b), são os compostos e as relações que suscitam as propriedades e, por conseguinte, é a atribuição que esclarece o atributo, então, para este autor, o conhecimento do simples não produz efeitos.

Partindo dessa compreensão, o estudo que será realizado em uma instituição da rede de EPCT estará amparado na epistemologia bachelardiana, dada a complexidade a que o tema avaliação de competência docente remete e à necessidade de compreender tanto as relações como os intervenientes vinculados às competências requeridas dos professores. Ademais, o ensino conforma a principal atividade do professor na instituição que será investigada.

O ensino é uma das mais antigas profissões, visto por muito tempo como um apostolado e um sacerdócio leigo. Dentre as qualidades requeridas para seu exercício estavam as de cunho moral, que o bom mestre deveria possuir e exibir a todos aqueles que controlavam o seu trabalho, conforme Lessard e Tardif (2014). Para os autores, vocação, ofício e profissão são concepções que, apesar de exprimirem uma linha de evolução do ensino, encontram-se na ordem das representações dos construtos dos atores.

Portanto, ao passo que se enxerga o ensino a partir dessas três concepções, também é 


\section{OO DEVIR EDUCAÇÃO}

ISSN: 2526-849X

preciso superar as visões unidimensional e unidirecional, dando espaço ao devir da profissão docente, que só poderá ser desvelado no movimento constante de objetivação, complexificação e recomposição da (e pela) atividade.

Há que se considerar que os fundamentos do ensino são, a um só tempo, existenciais, sociais e pragmáticos. São existências, pois o professor pensa com a vida que viveu e com aquilo que acumulou de experiências e certezas. São sociais, uma vez que são plurais e provêm de fontes diversas, adquiridas em tempos sociais diferentes e legitimadas por determinados grupos. São pragmáticos porque são operativos e normativos, o que quer dizer que a sua utilização depende de sua adequação às funções, aos problemas e às situações de trabalho (TARDIF, 2011).

Souza (2016), referendada em Bachelard (1978a), lembra que o papel daquele que ensina é questionar as leis que constituíram fatos científicos, uma vez que estes substituíram conhecimentos anteriores e falhos. A autora destaca que, em Bachelard, reside um convite à dinâmica de ser ensinado e de ensinar como o único método de ensino e fío condutor de novas descobertas e experiências para professores e alunos.

As pesquisas de Tardif (2011) sobre a prática docente e a importância crítica da experiência apontam para a seguinte relação estabelecida entre os professores e seus saberes: são os saberes adquiridos através da experiência profissional que constituem os fundamentos de sua competência. Souza (2016) diz que a história do conceito de competência encontra-se assente na concepção de psicogenética das faculdades mentais, concebida como processo evolutivo da atividade humana, cuja base teórica se aporta em autores como Locke, Bruner, Spencer, Darwin, Bain, Dewey, Baldwin e Piaget.

As discussões empreendidas por Souza (2016) não só destacam a natureza polissêmica da noção de competência, mas, também, evidenciam a passagem do racional para o pragmático do conceito, uma vez que esse movimento exige que as instituições se transformem e se adaptem a novas combinações, incluindo a socialização de pessoas. A autora pontua que as três décadas às quais a palavra competência tem sido aplicada contribuíram não somente para a intensificação de seu uso, mas, também, para a prescrição de normas regulatórias das práticas profissionais.

Ela discute competência a partir de uma proposição em torno do fazer e do saber, pois, na perspectiva bachelardiana, só se pode afirmar que sabemos uma determinada coisa, embora a façamos, quando soubermos o que fazemos. Nesse sentido, as análises de Souza (2016) 


\section{OO DEVIR EDUCAÇÃO}

ISSN: 2526-849X

revelam a importância dada por Bachelard não só à conscientização entre o saber e o fazer, mas, sobretudo, aproximam o discurso desse filosofo à definição de competência profissional $^{8}$. Nas palavras da autora:

Sendo o nosso intuito abordar a competência docente, percebemos no discurso de Bachelard que as disciplinas científicas têm sido um entrave para a descoberta, pois não propicia aos discentes a experiência dos erros e do acerto. Essa tendência do docente de levar a experiência pronta no intuito de gerar o saber, entretanto não gera o espírito crítico que se é esperado. A este ponto Bachelard faz uma crítica, pois, o conhecimento que deveria impulsionar o pesquisador a avançar faz ele se satisfazer com os conceitos pré-estabelecidos. [...] Assim a competência docente é desgastada dentro do processo repetitivo do dia-a-dia, no qual se encontra professor-aluno. (SOUZA, 2016, p. 43).

Bachelard, ao concordar com a afirmação de que a melhor maneira de avaliar o rigor de uma ideia é ensinando-a, inscreve o ato de ensinar em sua epistemologia como oportunidade de aprendizado e retificação entre professores e alunos. Daí resulta o fato de que compreender é emergência do (e para) saber. Nesse sentido, discutir competência docente a partir desse entendimento é oportuno, uma vez que a intersubjetividade em torno da atividade do professor torna-se complexa e a insere em um movimento de constante recomposição.

Portanto, a confluência nas discussões de Costa (2015) e Souza (2016) sobre educação e competência à luz da epistemologia de Bachelard descortina a existência de um princípio formador direcionado para o professor e para o aluno, qual seja, a adaptação metodológica e a retificação como meios para superar os obstáculos epistemológicos.

Desse modo, o aporte bachelardiano à competência docente reside na compreensão em torno do aprimoramento contínuo dos conhecimentos e experiências pedagógicas do professor, necessários para que o mestre, na sua relação com o conhecimento e com seus alunos, transforme/retifique não somente o objeto de estudo, mas, também, o saber fazer frente aos alunos.

\section{Considerações complementares}

8 A competência profissional é uma combinação de conhecimentos, saber fazer, experiências e comportamentos que se exercem em um contexto preciso. Ela é constatada quando de sua utilização em situação profissional, a partir da qual é passível de validação. (ZARIFIAN, 2001 apud SOUZA, 2016, p. 43). 


\section{OO DEVIR EDUCAÇÃO}

ISSN: 2526-849X

O estudo bibliográfico empreendido na primeira etapa da pesquisa de doutorado em possibilitou apresentar quatro pistas circunscritas na epistemologia de Gaston Bachelard (1884-1962) que dialogam com o trabalho pedagógico do professor e, por conseguinte, com a prática avaliativa, quais sejam: (i) a retificação do conhecimento deve ser bússola orientadora tanto para a prática pedagógica como para as interações entre alunos e professores; (ii) a essência da avaliação é o aprimoramento constante do seu objeto de análise, estando contido nesta ideia um diálogo retificador entre as dimensões formativa e somativa da avaliação, uma vez que não existe verdade primeira, mas, sim, primeiros erros, e estes são fonte de aprendizado; (iv) a compreensão da ciência como ato, pois o caminho para a verdade pressupõe construção, criação e retificação do conhecimento.

A muldimensionalidade da docência, considerando, sobretudo, o âmbito da EPCT, complexifica as avaliações de desempenho docente instituídas na unidade analisada e, por isso, constitui-se em um obstáculo epistemológico para este estudo. Todavia, espera-se que os resultados da investigação possam contribuir de algum modo para o aprimoramento do projeto avaliativo institucional.

Portanto, as etapas seguintes da pesquisa em andamento irão considerar a intencionalidade retificadora do racionalismo aplicado de Bachelard, pois esta nutre e pode revivificar o ensino, a avaliação e a competência individual do professor em seus três macroelementos: os conhecimentos, as habilidades e as atitudes.

\section{Referências}

BACHELARD, Gaston. O novo espírito científico. Tradução: Remberto Francisco Kuhnen. Coleção Os Pensadores. São Paulo: Abril Cultural, 1978.

BACHELARD, Gaston. A filosofia do não: filosofia do novo espírito científico. Tradução: Joaquim José Moura Ramos. São Paulo: Abril Cultural, 1978.

BACHELARD, Gaston. A formação do espírito científico: contribuições para uma psicanálise do conhecimento. Tradução: Estrela dos Santos Abreu. Rio de Janeiro: Contraponto, 1996.

BACHELARD, Gaston. O Racionalismo aplicado. Tradução: Nathanaeel Caxeiro. Rio de Janeiro: Zahar Editores, 1977. 
COSTA, Celma Laurinda Freitas. Ciência e Educação em Bachelard. 2015. 201 f. Tese (Doutorado em Educação). Pontifícia Universidade Católica de Goiás, Goiânia, 2015.

BRUYNE, Paul de; HERMAN, Jacques; SCHOUTEETE, Marc de. Dinâmica da pesquisa em ciências sociais. Tradução Ruth Joffily. Rio de Janeiro: Francisco Alves Editora, 1977.

FONSECA, Dirce Mendes da. A Pedagogia Científica de Bachelard: uma reflexão a favor da qualidade e da prática e da pesquisa docente. Educação e Pesquisa. São Paulo. v.34, n.2, p. 371-370, mai./ago. 2008. Disponível em:<https://www.revistas.usp.br/ep/article/download/28093/2990. >. Acesso em: 27 mai 2018

JAPIASSU, Hilton Ferreira. Introdução ao pensamento epistemológico. Rio de Janeiro: Francisco Alves Editora, 1975.

LESSARD, Claude; TARDIF, Maurice. As transformações atuais do ensino: três cenários possíveis na evolução da profissão de professor. In:TARDIF, Maurice.; LESSARD, Claude. (orgs.). O Ofício de Professor: histórias, perspectivas e desafios internacionais. Petrópolis: Vozes, 2014. p. 255 -277.

LIMA, Marcos Antonio Martins. Autoavaliação institucional na educação superior: projeto aplicado em cursos de administração. Fortaleza: Edições UFC, 2008.

LIMA, Marcos Antonio Martins; MARINELLI, Marcos. A Epistemologia de Gaston Bachelard: uma ruptura com as filosofias do imobilismo. Revista de Ciências Humanas, Florianópolis, v.45, N2, p.393-406, Out. de 2011

LUCKESI, Carlos Cipriano. Avaliação da aprendizagem: componente do ato pedagógico. São Paulo: Cortez, 2011.

SCRIVEN, Michael. Avaliação: um guia de conceitos. Tradução: Marília Sette Câmara. Rio de Janeiro/São Paulo: Paz e Terra, 2018.

SOUZA, Andrea Moura da Costa. Avaliação docente em estágio probatório: estudo das ações educacionais do programa CASa/UFC - Comunidade de Cooperação e Aprendizagem Significativa. 2016. 173 f. Tese (Doutorado em Educação). Faculdade de Educação da Universidade Federal do Ceará (UFC), Ceará, Fortaleza, 2016.

TARDIF, Maurice. Saberes docentes e formação profissional. Petrópolis: Vozes, 2011.

VIANNA, Heraldo Marelim. Avaliação educacional: teoria, planejamento, modelos. São Paulo: IBRASA, 2000. 
Recebido em 15/07/2020

Aprovado em 20/08/2020

Revista Devir Educação, Lavras, vol.4, n.2, p.272-290 jul./dez., 2020. 